\title{
EFFECT OF NICKEL AND SILVER IONS ON SURVIVAL, GROWTH, CARBON FIXATION AND NITROGENASE ACTIVITY IN NOSTOC MUSCORUM: REGULATION OF TOXICITY BY EDTA AND CALCIUM
}

\author{
L. C. RAI AND MEENA RAIZADA \\ Laboratory of Algal Biology, Centre of Advanced Study in Botany, \\ Banaras Hindu University, Varanasi-221005, India
}

(Received July 29, 1985)

The effects of different concentrations of nickel $(2.1,4.2,5.04 \mu \mathrm{M})$ and silver $(0.013,0.026,0.052 \mu \mathrm{M})$ on survival, growth, carbon fixation and acetylene reduction of Nostoc muscorum has been studied. All concentrations of the heavy metals except $2.1 \mu \mathrm{M}$ Ni were inhibitory. At $2.1 \mu \mathrm{M}$, nickel chloride stimulated carbon fixation and nitrogenase activity. Silver seems to be much more toxic than nickel because concentrations as low as $0.026 \mu \mathrm{m}$ silver chloride inhibited approximately $90 \%$ of the carbon fixation. EDTA protected carbon fixation and calcium ameliorated the nitrogenase activity in the test alga. However, none of these ameliorative agents were so effective against silver toxicity. This study suggests that (i) calcium plays an imporatnt role in nitrogen fixation, (ii) like hydrogen production and uptake hydrogenase, nickel seems to have some role in regulating nitrogenase activity, and (iii) carbon fixation is a more sensitive parameter than growth and nitrogensase in evaluating metal toxicity.

A large number of aquatic habitats are becoming progressively more contaminated by the indiscriminate discharge of heavy metals generated from various industrial processes, modern agricultural practices, acid mine drainage and human wastes. The toxicity of heavy metals has long been recognized due to such outbreaks as those at Minamata, Niigata and elsewhere. Use of algae to monitor heavy metal toxicity is greatly increasing due to their ubiquity in aquatic ecosystems where they influence and are influenced by most aquatic processes. Algae incorporate solar energy into biomass, produce oxygen that is dissolved in water and used by aquatic organisms, function critically in the cycling and mineralization of chemical elements, and serve as food for herbivorous and omnivorous animals. A wealth of literature has been published dealing with the disastrous impact of 
heavy metals on taxonomic diversity and production of algae (1-4). However, these studies are concerned mainly with eucaryotic algae; information regarding cyanobacteria is lagging far behind.

Cyanobacteria are most important in the aquatic system as half of the nitrogen fixed in this system comes from them. Some work has been done on the toxicity of heavy metals in a few species of cyanobacteria; these are mostly confined to such parameters as growth, pigment synthesis, nutrient uptake, etc. $(5,6)$. Other important processes such as carbon fixation, and nitrogenase activity have been completely neglected. Henrickson and Dasilva (7) studied the effect of $\mathrm{Zn}, \mathrm{Cd}$, $\mathrm{Ni}, \mathrm{Pb}, \mathrm{As}$ and $\mathrm{Pd}$ on nitrogen fixation in Nostoc (a phycobiont), Chlorogloea fritschi and Nostoc muscorum. Stratton and Corke $(8-10)$ studied the interactive effect of $\mathrm{Hg}^{2+}, \mathrm{Cd}^{2+}$ and $\mathrm{Ni}^{2+}$ on nitrogen and carbon fixation of Anabaena inaequalis. Apparently no other work has been done to date on the effect of heavy metals on carbon and nitrogen fixation by cyanobacteria.

RAI et al. (l) gave a critical account of the effect of environmental factors on the toxicity of heavy metals in algae. Similar studies of cyanobacteria have also been done (11-13). These studies and others (14-16) have suggested that the toxicity of heavy metals can be ameliorated by EDTA and calcium. In a recent study, Schecher and Driscoll (13) reported that the uptake of $\mathrm{Cu}$ and $\mathrm{Pb}$ by Nostoc muscorum can be reduced by $10^{-3} \mathrm{M}$ calcium. They suggested that this may be due to competition between calcium and metals for active surface sites. The present study is of particular interest because nothing is known about (i) the effect of silver on cyanobacterium, (ii) the effect of silver and nickel on carbon and nitrogen fixation by Nostoc muscorum and (iii) the effect of EDTA and calcium in regulating the toxicity of silver and nickel in Nostoc.

Inspired by these considerations and also following the isolation of a nickeldependent Oscillatoria 3NT and the indication of the possible role of nickel in hydrogen production and uptake hydrogenase (17-19), we undertook the present study.

\section{MATERIALS AND METHODS}

Organism and growth conditions. The test alga N. muscorum ISU (Anabaena ATCC 27893) was raised in modified $\mathrm{CHU}_{10}$ medium (20). Cultures received 2500 lux light intensity in a $14 \mathrm{hr}$ light and $10 \mathrm{hr}$ dark cycle at $25 \pm 1{ }^{\circ} \mathrm{C}$. These incubation conditions were standard for all growth, photosynthesis and acetylene reduction experiments.

Measurement of survival and growth. Stock solutions of $\mathrm{NiCl}_{2} \cdot 6 \mathrm{H}_{2} \mathrm{O}$ and $\mathrm{AgCl}$ were filter-sterilized by passage through millipore membrane filters $(0.45 \mu \mathrm{m})$ before diluting and adding them to the algal cultures. The survival percentage of N. muscorum in culture media containing different concentrations of nickel chloride $(2.1,4.2$ and $5.04 \mu \mathrm{M})$ and silver chloride $(0.013,0.026$ and $0.052 \mu \mathrm{M})$ was studied 


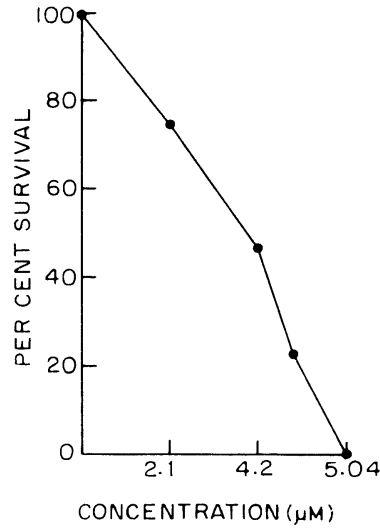

Fig. 1. Survival of $N$. muscorum at different concentrations of nickel chloride.

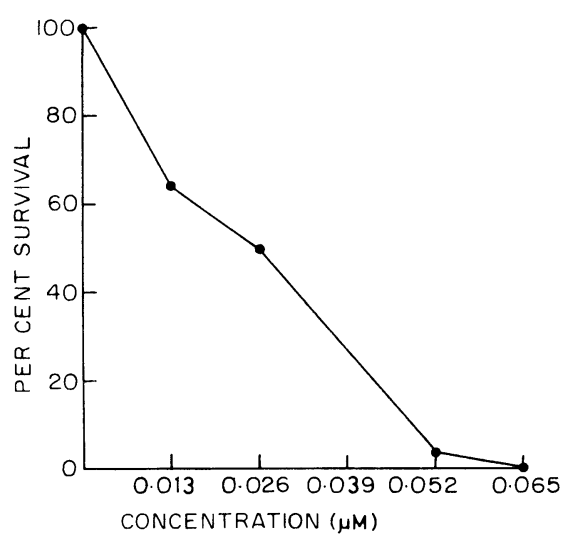

Fig. 2. Survival of N. muscorum at different concentrations of silver chloride.

by the plate/colony count method. A $0.02 \mathrm{ml}$ aliquot of exponentially growing Nostoc containing $10^{4}$ cells $/ \mathrm{ml}$ was aseptically spread onto agar plates supplemented with various concentrations of test metals. Colonies were counted after 3 weeks with a colony counter and the survival percentage was scored (Figs. 1, 2). Nickel and silver chlorides at concentrations of 4.2 and $0.026 \mu \mathrm{M}$ respectively allowed approximately $50 \%$ survival; these concentrations of test metals were therefore referred to as sublethal concentrations.

Fifty milliliters of culture medium in $150 \mathrm{ml}$ Erlenmeyer flasks was used for growth studies. On every third day, a culture suspension was aseptically withdrawn and the optical density of the suspension was recorded at $663 \mathrm{~nm}$ in a Bausch and Lomb spectronic-20 spectrophotometer. The effect of heavy metals on growth was studied by supplementing the culture flasks with known concentrations of the test metals. Growth was measured in terms of final yield (expressed as optical density) attained on the 15th day and converted to percentage of the control for comparison. In order to avoid any change in $\mathrm{pH}$, the culture medium was buffered with Tris (Sigma grade) buffer ( $\mathrm{pH} 7.5$ ). Concentrations of $\mathrm{CaCl}_{2}$ and EDTA (ethylenediaminetetraacetic acid) used for different experiments were 181.0 and $34.0 \mu \mathrm{M}$ respectively.

Acetylene reduction. Nitrogenase activity was measured by the acetylene reduction technique $(21)$. The assay was performed in triplicate in serum bottles of about $7.5 \mathrm{ml}$ capacity. The acetylene concentration was kept at $10 \%$ and a $2 \mathrm{ml}$ cell suspension was routinely injected in each bottles. Reactions were terminated by injecting $0.8 \mathrm{ml}$ of $15 \%(\mathrm{w} / \mathrm{v})$ trichloroacetic acid. Ethylene produced in the reaction vessel was analysed in a CIC gas chromatograph fitted with a porapak $\mathrm{R}$ column and a hydrogen flame ionization detector.

Carbon fixation. This was assayed following the uptake of ${ }^{14} \mathrm{CO}_{2}$ from $\mathrm{NaH}$ 
Table 1. Effect of different concentrations of $\mathrm{Ni}$ and $\mathrm{Ag}$ on the growth behaviour of $N$. muscorum supplemented with EDTA and calcium.

\begin{tabular}{|c|c|c|}
\hline \multirow{2}{*}{ Concentration $(\mu \mathrm{M})$} & \multicolumn{2}{|c|}{ Final yield attained on 15 th day } \\
\hline & Mean value \pm S.D. & Percentage of control \\
\hline Control & $0.51 \pm 0.007$ & 100.00 \\
\hline Control $+\mathrm{Ca}^{a}$ & $0.55 \pm 0.007$ & 107.84 \\
\hline Control + EDTA $^{a}$ & $047+0.001$ & 90.00 \\
\hline $2.1 \mathrm{Ni}$ & $047+0.003$ & 90.19 \\
\hline $2.1 \mathrm{Ni}+\mathrm{Ca}$ & $049 \pm 0.001$ & 95.15 \\
\hline $2.1 \mathrm{Ni}+$ EDTA & $048 \pm 0.007$ & 92.23 \\
\hline $4.2 \mathrm{Ni}$ & $0.27 \pm 0001$ & 52.94 \\
\hline $4.2 \mathrm{Ni}+\mathrm{Ca}$ & $0.38 \pm 0.003$ & 66.66 \\
\hline $4.2 \mathrm{Ni}+\mathrm{EDTA}$ & $0.36 \pm 0007$ & 70.58 \\
\hline $5.04 \mathrm{Ni}$ & $0.12 \pm 0.001$ & 23.52 \\
\hline $5.04 \mathrm{Ni}+\mathrm{Ca}$ & $0.30 \pm 0.002$ & 58.82 \\
\hline $5.04 \mathrm{Ni}+$ EDTA & $0.33 \pm 0.001$ & 64.70 \\
\hline $0.013 \mathrm{Ag}$ & $0.35 \pm 0.007$ & 68.43 \\
\hline $0.013 \mathrm{Ag}+\mathrm{Ca}$ & $0.45+0.003$ & 88.23 \\
\hline $0.013 \mathrm{Ag}+\mathrm{EDTA}$ & $0.44 \pm 0.001$ & 86.27 \\
\hline $0.026 \mathrm{Ag}$ & $0.28+0.011$ & 54.90 \\
\hline $0.026 \mathrm{Ag}+\mathrm{Ca}$ & $0.36 \pm 0.001$ & 70.58 \\
\hline $0.026 \mathrm{Ag}+$ EDTA & $0.35 \pm 0.003$ & 68.62 \\
\hline $0.052 \mathrm{Ag}$ & $0.20 \pm 0.004$ & 39.21 \\
\hline $0.052 \mathrm{Ag}+\mathrm{Ca}$ & $0.29 \pm 0.001$ & 56.86 \\
\hline $0.052 \mathrm{Ag}+\mathrm{EDTA}$ & $0.26 \pm 0.005$ & 50.98 \\
\hline
\end{tabular}

$a$ Concentrations of $\mathrm{Ca}$ and EDTA were 181.0 and $34.0 \mu \mathrm{M}$ respectively.

${ }^{14} \mathrm{CO}_{3}$. Algal suspensions treated with sublethal concentrations of nickel and silver were supplemented with $50 \mu \mathrm{l}$ of radioisotope to give a final activity of $0.026 \mu \mathrm{Ci}$ / $\mathrm{ml}$. The activity was assayed every $30 \mathrm{~min}$ for $2 \mathrm{hr}$ with the help of a Beckman model-LS 7000 scintillation counter.

\section{RESULTS AND DISCUSSIONS}

Effect of nickel and silver on growth: Interaction with EDTA and calcium

Table 1 summarises the effect of three different concentrations of nickel and silver on the growth of $N$. muscorum. A gradual reduction in growth in terms of final yield attained on the 15th day has been noticed at the concentrations of the test metals used. Nickel at a concentration of $4.2 \mu \mathrm{M}$ reduced the final yield by $53 \%$. However, the concentration of silver required to reduce the final yield by $55 \%$ was only $0.026 \mu \mathrm{M}$. This suggests a greater toxic potential of Ag compared to $\mathrm{Ni}$.

The protective effects of EDTA and calcium found here is in agreement with earlier findings $(1,11)$. Calcium and EDTA are widely known to form complexes 
with metals and decrease their availability and hence reduce the toxicity. The better growth restoration by EDTA and calcium observed with $\mathrm{Ni}$ than with $\mathrm{Ag}$ may be due to the differential binding capacity of the metals. Chelators are also known to alter the transport system (22) and reduce toxicity. Another probable reason for growth restoration by $\mathrm{Ni}$ could be its requirement in trace quantities as already reported for Oscillatoria $3 \mathrm{NT}$ (17). Since the concentration of Ni in the culture medium is much higher than $\mathrm{Ag}$, it is likely that some $\mathrm{Ni}$ may be left over after the complex formation with EDTA. This left-over Ni may serve the Ni requirement of Nostoc. Notwithstanding this, several of the cyanobacteria tested are known to be tolerant to nickel (23). Thus the better growth observed in our experiments may be due also to the tolerance of the test alga.

Growth restoration by calcium follows almost the same pattern observed for EDTA. Adding of calcium stimulated growth in the control (lacking Ni). Comparatively better growth was found in culture flasks containing $\mathrm{Ni}+\mathrm{Ca}$ than those containing $\mathrm{Ni}+$ EDTA. This confirms the growth stimulatory role of calcium in Nostoc. In addition to this, calcium is also known to protect algae, fungi and other microbes against the toxicity of $\mathrm{Cd}, \mathrm{Hg}, \mathrm{Cu}, \mathrm{Zn}$, etc., by precipitation, coprecipitation and complex formation $(1,24)$.

\section{Effect of $\mathrm{Ni}$ and $\mathrm{Ag}$ on carbon fixation: Interaction with EDTA and calcium}

The effect of $\mathrm{Ni}$ and $\mathrm{Ag}$ on carbon fixation in $N$. muscorum as influenced by calcium and EDTA is summarized in Table 2. DE FilipPis and Pallaghy (25) critically demonstrated inhibition of photosynthesis by mercury and zinc in Chlorella. That photosynthesis is the most sensitive parameter in Chlorella and other algae is well authenticated $(1,16,25)$. Our studies on Nostoc fully supports the findings of STRATTON and CORKE (8-10) in Anabaena inaequalis. Approximately $90 \%$ inhibition of ${ }^{14} \mathrm{C}$ uptake occurred at the sublethal concentration of silver; the inhibition was very prominent in the first $30 \mathrm{~min}$ of the experiment. In contrast to this, nickel only mildly (only $39 \%$ ) inhibits ${ }^{14} \mathrm{C}$ uptake. This mild toxicity of $\mathrm{Ni}$ may be due to slow uptake by Nostoc. Since the ${ }^{14} \mathrm{C}$ uptake experiments were conducted for only $2 \mathrm{hr}$, the alga may not have had enough time to take up the nickel.

Interaction studies with calcium and EDTA on ${ }^{14} \mathrm{C}$ uptake as influenced by $\mathrm{Ni}$ and $\mathrm{Ag}$ indicated that culture media supplemented separately with calcium and EDTA inhibited growth about $34 \%$ and $19 \%$ respectively in the first $30 \mathrm{~min}$ of the experiment. $\mathrm{Ca}$ and EDTA supplementation in the medium containing $\mathrm{Ni}$ and $\mathrm{Ag}$ produced different results. The flasks containing $\mathrm{Ni}+\mathrm{Ca}$ showed only $23 \%$ inhibition compared to the control (34\% inhibition). In contrast to this the medium containing $\mathrm{Ni}$ and EDTA showed almost the same amount of ${ }^{14} \mathrm{C}$ uptake as the control. Thus a $39 \%$ reduction of ${ }^{14} \mathrm{C}$ uptake by $4.2 \mu \mathrm{m}$ nickel was almost completely counteracted by the EDTA supplementation (Table 2). Another possibility may be that EDTA facilitates low level uptake of nickel. 
Table 2. Effect of sublethal concentrations of $\mathrm{Ni}$ and $\mathrm{Ag}$ on carbon fixation in N. muscorum: Interaction with calcium and EDTA.

\begin{tabular}{|c|c|c|c|c|}
\hline \multirow{2}{*}{ Concentration $(\mu \mathrm{M})$} & \multicolumn{4}{|c|}{ CPM (hr) } \\
\hline & 0 & $1 / 2$ & 1 & 2 \\
\hline Control & 9800 & 657.60 & 1105.80 & 1673.80 \\
\hline Control $+\mathrm{Ca}^{a}$ & 9800 & $\begin{array}{l}435.40 \\
(33.79)^{b}\end{array}$ & $\begin{array}{c}631.60 \\
(42 \quad 80)\end{array}$ & $\begin{array}{r}1163.40 \\
(30 \quad 49)\end{array}$ \\
\hline Control $+\mathrm{EDTA}^{a}$ & 9800 & $\begin{array}{l}530.00 \\
(19.40)\end{array}$ & 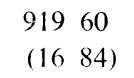 & $\begin{array}{c}995.80 \\
(46.80)\end{array}$ \\
\hline $4.2 \mathrm{Ni}$ & 9800 & $\begin{array}{l}401.60 \\
\left(\begin{array}{ll}38 & 93\end{array}\right)\end{array}$ & 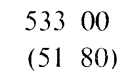 & $\begin{array}{r}1009.20 \\
(39.71)\end{array}$ \\
\hline $4.2 \mathrm{Ni}+\mathrm{Ca}$ & 9800 & $\begin{array}{l}506.20 \\
(23.02)\end{array}$ & $\begin{array}{l}765.20 \\
(30.80)\end{array}$ & $\begin{array}{r}1021.40 \\
(38.97)\end{array}$ \\
\hline $4.2 \mathrm{Ni}+$ DETA & 98.00 & $\begin{array}{r}651.80 \\
(0.88)\end{array}$ & $\begin{array}{l}908.20 \\
(17.87)\end{array}$ & $\begin{array}{r}1449.40 \\
(1339)\end{array}$ \\
\hline $0.026 \mathrm{Ag}$ & 9800 & $\begin{array}{c}73.80 \\
(88.81)\end{array}$ & $\begin{array}{l}125.40 \\
(88 \quad 66)\end{array}$ & $\begin{array}{l}170.20 \\
\left(\begin{array}{ll}89 & 84\end{array}\right)\end{array}$ \\
\hline $0.026 \mathrm{Ag}+\mathrm{Ca}$ & 9800 & $\begin{array}{c}75.00 \\
(88.59)\end{array}$ & 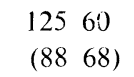 & $\begin{array}{c}16090 \\
(90.44)\end{array}$ \\
\hline $0.026 \mathrm{Ag}+\mathrm{EDTA}$ & 9800 & $\begin{array}{c}76.90 \\
(88.31)\end{array}$ & $\begin{array}{l}140.60 \\
(87.29)\end{array}$ & $\begin{array}{l}179.40 \\
\left(\begin{array}{ll}89 & 20\end{array}\right)\end{array}$ \\
\hline
\end{tabular}

The higher ${ }^{14} \mathrm{C}$ uptake by the Nostoc treated with $\mathrm{Ni}$ in the presence of calcium may be simply due to calcium protection against nickel toxicity. However, the toxic effect of silver on ${ }^{14} \mathrm{C}$ uptake does not seem to be controlled either by calcium or EDTA. The silver-induced inhibition $(88 \%)$ never recovered even after addition of Ca or EDTA. Thus silver seems to have a highly toxic effect on carbon fixation in N. muscorum.

Effect of $\mathrm{Ni}$ and $\mathrm{Ag}$ on acetylene reduction: Interaction with calcium and EDTA

The effect of different concentrations of nickel and silver on acetylene reduction by $N$. muscorum is summarized in Table 3. Maximum inhibition of nitrogenase by $\mathrm{Ni}$ and $\mathrm{Ag}$ occurred after $48 \mathrm{hr}$ of treatment followed by a gradual recovery at $72 \mathrm{hr}$ in the case of $\mathrm{Ni}$. But with silver nitrogenase activity does not recover. At $2.1 \mu \mathrm{M}$ of $\mathrm{Ni}$ there was $8 \%$ stimulation of nitrogenase activity after $24 \mathrm{hr}$ of incubation, followed by $11 \%$ after $48 \mathrm{hr}$ and only $3 \%$ after $72 \mathrm{hr}$. Like silver, higher concentrations $(4.2 \mu \mathrm{M}, 5.04 \mu \mathrm{M})$ of nickel inhibited enzyme activity. Stimulation of nitrogenase by low levels of nickel may be due either to direct induction or altered nutrient flow. As in Chlorella (27) the test alga may counteract the toxicity by binding ions to metabolically maintained "indifferent sites." Such sites are likely to be created at a faster rate under nickel stress.

Calcium supplementation stimulates nitrogenase activity (Table 4), but EDTA 
咅:

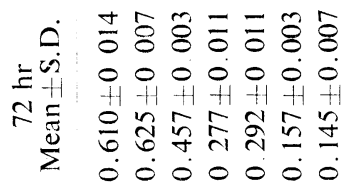

.

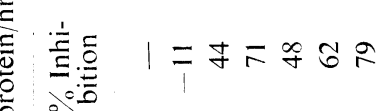

驾

I

En 000000000

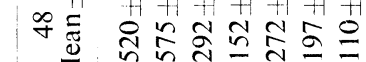

0000000

官 1 i

要

$\stackrel{\infty}{=}$

艺

En 0000000

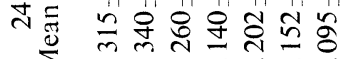
००000000

Z

$\underset{\mathscr{E}}{\mathscr{E}}$

$\dot{m}$

$\frac{0}{\frac{0}{0}}$
峁

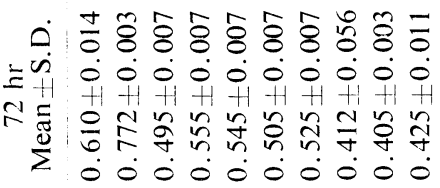

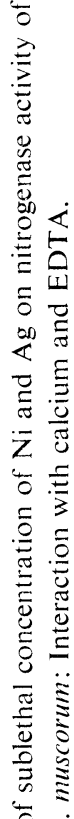

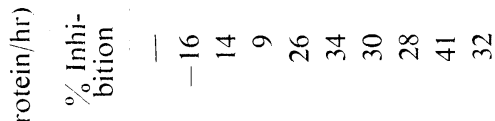

ค En 0 i 00 o

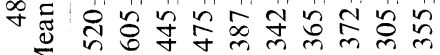
0000000000

施

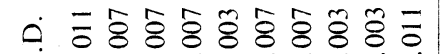
=

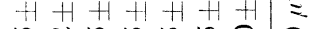

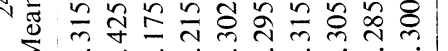
0 000000000

1

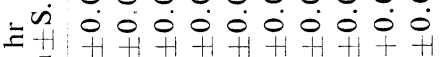

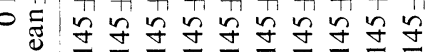
0000 000000 $\dot{+}$

$\frac{0}{\circ}$ $\underset{+}{*}$

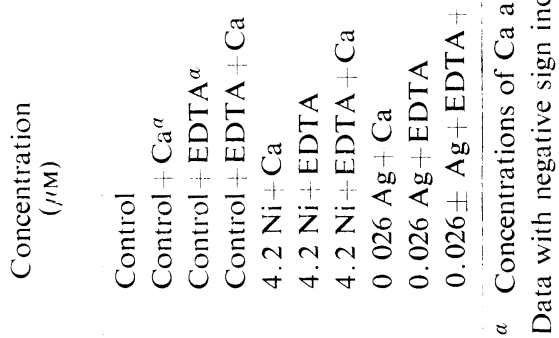


supplementation inhibits it. EDTA toxicity may be due to the fact that it is a polar molecule which does not enter the cell. EDTA may inhibit acetylene reduction in Nostoc by decreasing the external concentration of divalent cations such as calcium, etc. This seems reasonable because adding calcium to EDTA-supplemented culture counteracts the toxicity and decreases nitrogenase inhibition. Our observations parallel those of GALLON (28) who found that calcium stimulates nitrogenase activity in Gloeocapsa. In the present study, calcium was found to ameliorate silver toxicity to nitrogenase, though the leval of protection was much less than with nickel.

Stimulation of $\mathrm{N}_{2}$ ase activity by nickel can also be explained in the light of recent findings $(18,19)$ suggesting the existence of nickel-dependent hydrogen production and uptake hydrogenase activity in the two cyanobacteria Anabaena CA and Anabaena variabilis. Further the hydrogen dependent nitrogenase activity (acetylene reduction) has already been reported in several cyanobacteria, especially under reductant limiting conditions (29). Since nickel is now known to stimulate hydrogen uptake, it is likely that excess hydrogen taken up by the test alga may offer reducing power to nitrogenase thereby stimulating the activity of the enzyme. GALLON (28) reported that nitrogen fixation by heterocystous blue-green algae is insensitive to EDTA. Our findings, however, do not agree with that. We observed significant inhibition of nitrogenase activity by EDTA in N. muscorum.

Metals may be toxic to nitrogenase in many different ways: (i) there can be direct action on enzyme complex, or (ii) there may be an effect on the supply of ATP or reductant pool which are prerequisites for enzyme activity. Since photosynthesis is the main source of ATP and reductant in cyanobacteria, inhibition of this process can bring about reduction in ATP and reductant. Tremendous ininhibition ( $88 \%$, Table 2$)$ of carbon fixation by silver seems to a have direct bearing on nitrogenase activity. Our observations suggest that carbon fixation is the most sensitive parameter in $N$. muscorum as compared to growth and nitrogen fixation. Looking at the stimulatory effect of $\mathrm{Ni}$ (at low concentrations only) on carbon fixation and nitrogenase activities and also keeping in view the pioneer findings of VAN BAALEN and O'DONELL $(17)$ and others $(18,19)$ it seems plausible to include nickel in the category of essential elements. However, this warrants further research.

We are thankful to the Head, Department of Botany and Prof. H. D. Kumar, Program Coordinator, Centre of Advanced Study in Botany for laboratory facilities. One of us (Raizada) expresses gratitude to B.H.U. for financial assistance in the form of a fellowship.

\section{REFERENCES}

1) L. C. Rai, J. P. Gaur and H. D. Kumar, Biol. Rev., 56, 99 (1981).

2) P. M. Stokes, In Progress in Phycological Research, Vol. II, ed. by F. E. Round and V. J. Chapman, Elsevier Science Publisher B. V. (1983), p. 87. 
3) A. G. Davies, In Progress in Phycological Research, Vol. II, ed. by F. E. Round and V. J. Chapman, Elsevier Science Publisher B. V. (1983), p. 112.

4) B. A. Whitton, In Algae as Ecological Indicators, Academic Press, London (1984), p. 257.

5) S. P. Singh and V. Yadava, J. Gen. Appl. Microbiol., 30, 79 (1984).

6) M. Raizada, L. C. Ral, and S. K. Dubey, Adv. Biol. Res., 1/2, 46 (1984).

7) L. E. Henriksson and E. J. Dasilva, Z. Allge. Mikrobiol., 18, 487 (1978).

8) G. W. Stratton and C. T. Corke, Chemosphere, 5, 277 (1979).

9) G. W. Stratton and C. T. Corke, Chemosphere, 10, 731 (1979).

10) G. W. Stratton, A. L. Huber, and C. T. Corke, Appl. Environ. Microbiol, 38, 537 (1979).

11) S. P. Singh and A. K. Pandey, Environ. Exp. Bot., 21, 257 (1981).

12) A. Les and R. W. Walker, Water, Air, Soil Pollut., 23, 129 (1983).

13) W. D. Schecher and C. T. Driscoll, Water, Air, Soil Pollut., 24, 85 (1985).

14) L. C. Rai and N. Khatoniar, Ind. J. Enivron. Health., 22, 113 (1980).

15) L. C. RAI and R. DeY, Acta Hydrochim. Hydrobiol., 8, 319 (1980).

16) L. C. Ral, J. P. Gaur and H. D. Kumar, Environ. Res., 25, 250 (1981).

17) C. Van BaAlen and R. O'Donnell, J. Gen. Microbiol., 105, 351 (1978).

18) H. ALmon and P. Boger, Z. Naturforch., 39C, 90 (1983).

19) Z. Xiankong, F. R. Tabita, and C. Van BaAlen, J. Gen. Microbiol., 130, 1815 (1984).

20) G. C. Gerloff, G. P. Fitzgerald, and F. Skoog, Am. J. Bot., 37, 216 (1950).

21) R. W. F. Hardy, R. C. Burns, and R. D. Holsten, Soil Biol. Biochem., 5, 47 (1973).

22) C. D. Foy, R. L. Chaney, and M. C. White, Ann. Rev. Plant Physiol., 29, 511 (1978).

23) D. F. Spencer and R. W. Greene, Environ. Pollut., 25, 241 (1981).

24) G. M. Gadd and A. J. Griffiths, Microb. Ecol., 4, 303 (1978).

25) L. E. Defilippis and C. K. Pallaghy, Z. Pflanz., 78, 314 (1976).

26) S. S. Greenfield, Am. J. Bot., 29, 121 (1942).

27) L. Kamp-Nielsen, Physiol. Plant., 24, 556 (1971).

28) J. R. Gallon, Ecol. Bull., 26, 60 (1978).

29) G. R. Lambert and G. D. Smith, Biol. Rev., 56, 589 (1981). 